\title{
BEZŁOŻYSKOWE MASZYNY ELEKTRYCZNE W KONCEPCJI MORE ELECTRIC AIRCRAFT
}

\begin{abstract}
Obecnie w lotnictwie trwa dynamiczny rozwój wyposażenia pokładowego statków powietrznych związany z wdrażaniem technologii More Electric Aircraft, która zakłada stosowanie większej liczby systemów wykorzystujących energię elektryczną. Koncepcja ta oferuje możliwości poprawienia warunków użytkowania instalacji i układów wynikających ze zmniejszenia masy, rosnącej niezawodności urządzeń, łatwiejszej konserwacji, a przez to zwiększenie bezpieczeństwa lotu. W odpowiedzi na te tendencje w Zakładzie Awioniki i Uzbrojenia Lotniczego Wojskowej Akademii Technicznej są opracowywane konstrukcje bezłożyskowych maszyn elektrycznych (silniki, prądnice, prądnico-rozruszniki itp.). W pracy przedstawiono przykładowe rozwiązanie, tj. bezłożyskowy silnik elektryczny z magnesami trwałymi. Konstrukcja bezłożyskowego silnika elektrycznego, zaprojektowana zgodnie z koncepcją More Electric Aircraft, jest ukierunkowana na eliminację elementów ograniczających szybkość działania, jak również na poprawę parametrów pracy oraz warunków eksploatacji. Przedstawiono model matematyczny takiego silnika oraz wyniki badań symulacyjnych i eksperymentalnych.
\end{abstract}

Słowa kluczowe: bezłożyskowe maszyny elektryczne, statki powietrzne, niezawodność

\section{Bezłożyskowy silnik elektryczny}

Silnikiem bezłożyskowym określa się maszynę elektryczną, w której pole magnetyczne wytwarza, oprócz momentu obrotowego, siły lewitacji magnetycznej. W silniku takim klasyczne łożyska kulkowe zostały zastąpione aktywnym zawieszeniem magnetycznym. Dzięki temu zostały wyeliminowane siły tarcia między wirnikiem a statorem silnika, usunięto negatywne cechy eksploatacyjne takiego układu, tj. nagrzewanie i zużywanie się elementów trących, smarowanie, wydzielanie ciepła i hałasu [1]. Silnik elektryczny z magnesami trwałymi (rys. 1.) został zrealizowany według reguły $p \pm 1$ nawinięcia uzwojeń statora,

\footnotetext{
${ }^{1}$ Krzysztof Falkowski, Wojskowa Akademia Techniczna, ul. S. Kaliskiego 2, 00-908 Warszawa, e-mail: krzysztof.falkowski@wat.edu.pl

2 Autor do korespondencji/corresponding author: Maciej Henzel, Wojskowa Akademia Techniczna, ul. S. Kaliskiego 2, 00-908 Warszawa, tel.: (22) 6839858, e-mail: maciej.henzel@ wat.edu.pl
} 
ponieważ uzwojenie łożyskowe musi być modulowane do napięć zasilających uzwojenia silnikowego z dwa razy mniejszą częstotliwością zasilania. I tak, uzwojenie czterobiegunowe jest przeznaczone do wytwarzania momentu obrotowego, natomiast uzwojenie dwubiegunowe odpowiada za lewitację magnetyczną.

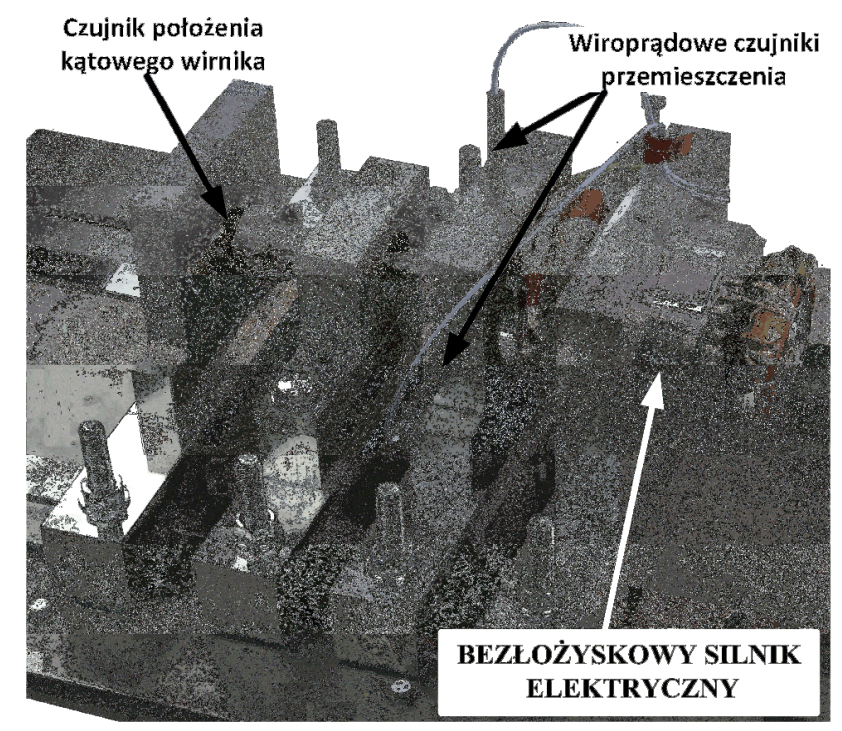

Rys. 1. Bezłożyskowy silnik elektryczny z magnesami trwałymi $[1,2]$

Fig. 1. The bearingless electric motor with permanent magnets $[1,2]$

Na rysunku 2. przedstawiono rozkład uzwojeń wraz z generowanymi strumieniami magnetycznymi. Zgodnie z przyjętymi oznaczeniami strumienie wytworzone przez uzwojenia lewitacyjne w szczelinach „1”, „2", „3" i „4” sumują się ze strumieniami generowanymi przez uzwojenia silnikowe. Sterowanie ruchem wirnika w kierunku osi $0 x$ przedstawiono na rys. 3. Strumień magnetyczny generowany przez uzwojenia silnikowe w szczelinie „1" posiada zwrot dodatni, a w szczelinie ,3" strumień wytwarzany przez uzwojenia silnikowe ma kierunek przeciwny. Jeżeli wirnik pozostaje $\mathrm{w}$ położeniu nominalnym, to w uzwojeniach sterujących nie płynie prąd. Generowane siły magnetyczne posiadają tą samą wartość i przeciwny kierunek - wypadkowa siła działająca na wirnik jest równa zeru. Jeżeli wirnik przemieści się, to układ sterowania zmieni prąd w uzwojeniach silnikowych, przeciwdziałając ruchowi wirnika. Strumienie magnetyczne uzwojeń $N_{m a}$ i $N_{s a}$ w szczelinie „1" sumują się, a w szczelinie „,3” odejmują (rys. 3a). Wypadkowa siła magnetyczna będąca różnicą sił w szczelinie „1” i „,3” przeciwdziała ruchowi wirnika (rys. 3b). Zmiana kierunku ruchu wirnika powo- 
duje zmianę kierunku strumienia magnetycznego. Strumienie magnetyczne w szczelinie „1" odejmują się, a w szczelinie ,3” dodają. Prowadzi to do wygenerowania przeciwnie skierowanej siły różnej od zera $[2,3]$.

a)

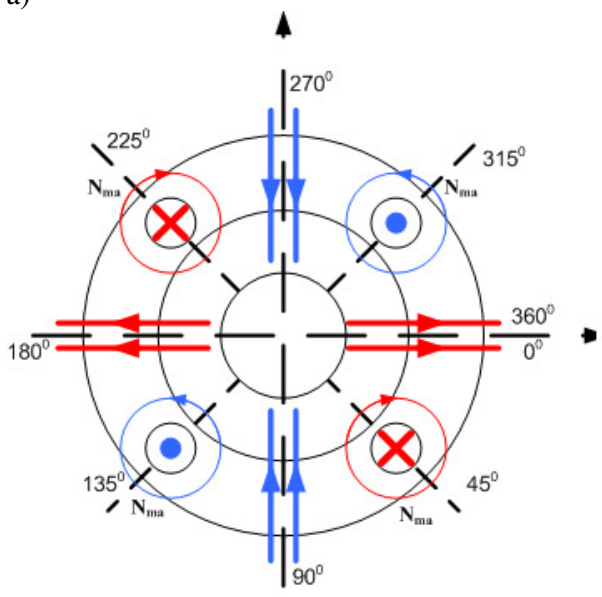

b)

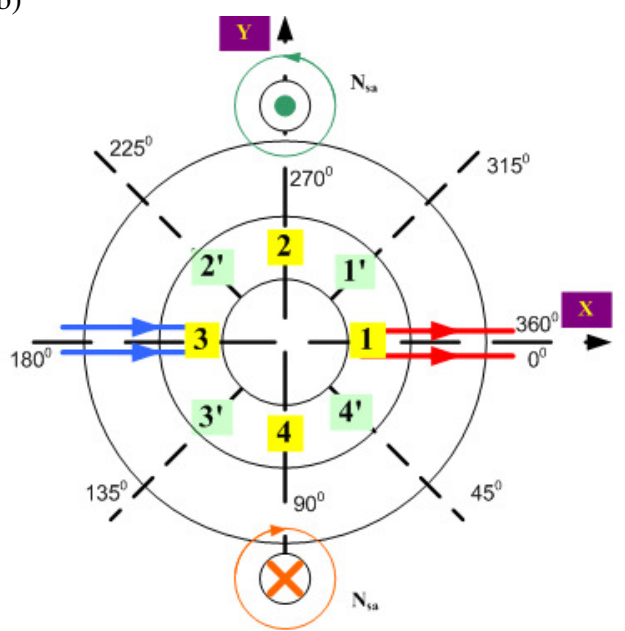

Rys. 2. Strumień magnetyczny generowany przez uzwojenia silnikowe (a) i lewitacyjne (b)

Fig. 2. Magnetic flux generated by motorized (a) and levitational (b) winding

a)

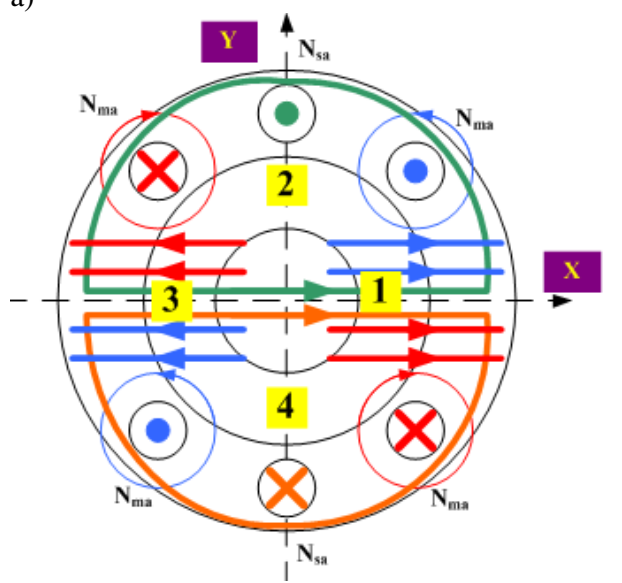

b)

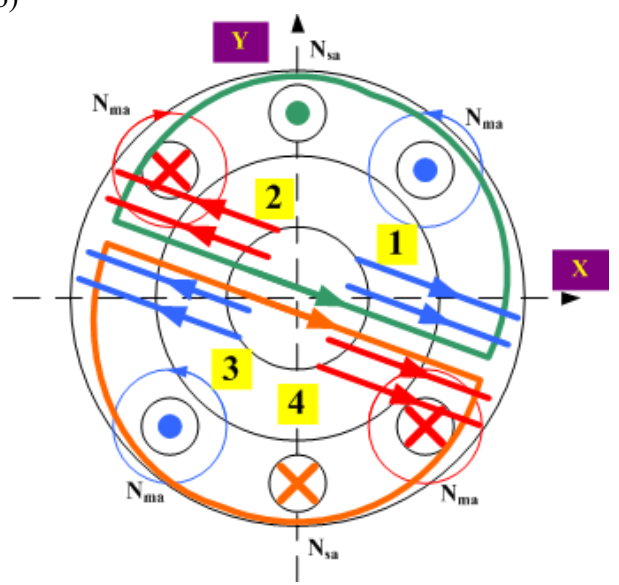

Rys. 3. Wygenerowanie siły magnetycznej: a) przeciwdziałającej ruchowi wirnika w kierunku szczeliny „3”, b) zmiana orientacji strumienia magnetycznego w silniku bezłożyskowym [2]

Fig. 3. Generation of magnetic force: a) counteract rotor rotation in direction of „3” gap, b) variation of magnetic flux orientation in the bearingless motor [2] 
Dokonując pomiaru położenia wirnika względem nabiegunników silnika bezłożyskowego, można tak zmieniać wartość prądu w uzwojeniach lewitacyjnych, aby wirnik zawsze zajmował stałe położenie. Jeżeli zamiast prądu stałego w uzwojeniu silnikowym popłynie prąd przemienny, to wytworzy się moment obrotowy. Strumienie magnetyczne generowane przez uzwojenie silnikowe zmienią swoją orientację. Utrzymanie stabilnego położenia wirnika w szczelinie powietrznej wymaga, aby strumień sterujący położeniem również się obracał; ponieważ strumień magnetyczny jest przez uzwojenia umieszczony w statorze, to zmianę strumienia można wymusić przez generowanie jego składowych. Efekt taki uzyskuje się przez modulację składowych prądu w funkcji prędkości kątowej wirnika. W silniku bezłożyskowym można wykorzystać magnesy trwałe umieszczone na wirniku. Magnesy wytwarzają strumień magnetyczny, którego rozkład jest zbliżony do strumienia wytwarzanego przez uzwojenia silnikowe w maszynie elektrycznej bez magnesów. W takiej konstrukcji do sterowania położeniem wirnika w szczelinie powietrznej nie jest konieczne zasilanie uzwojeń silnikowych.

\section{Model matematyczny bezłożyskowego silnika elektrycznego}

Silnik bezłożyskowy rozpatruje się jako podporę lub napęd elektryczny ze względu na połączenie $\mathrm{w}$ jednym urządzeniu funkcji zawieszenia magnetycznego i silnika elektrycznego. Ruch wirnika jest opisany równaniami równowagi sił i momentów [1, 4]:

$$
\left.\begin{array}{l}
m \frac{\mathrm{d}^{2} x}{\mathrm{~d} t^{2}}=F_{e x}+G_{x} \\
m \frac{\mathrm{d}^{2} y}{\mathrm{~d} t^{2}}=F_{e y}+G_{y} \\
J \frac{\mathrm{d} \omega_{z}}{\mathrm{~d} t}=M_{z}-M_{0}
\end{array}\right\}
$$

gdzie: $x, y \quad$ - przemieszczenie wirnika w osi $O x$ i $O y$,

$\omega_{z} \quad$ - prędkość kątowa wirnika,

$F_{e x}, F_{e y}$ - siła elektromagnetyczna w osi $O x$ i $O y$,

$M_{z} \quad$ - moment siły elektromagnetycznej

$m \quad$ - masa wirnika,

$J \quad-$ moment bezwładności w osi $O z$,

$G_{x}, G_{y}$ - siła zewnętrzna działająca na wirnika w kierunku osi $O x$ i $O y$,

$M_{o} \quad$ - moment obciążający silnik. 
Siły wytrącające wirnik z położenia nominalnego obejmują składowe deterministyczne (radialne siły obciążające wirnik, siły grawitacji itp.) oraz składowe stochastyczne sił zewnętrznych przyłożonych do wirnika. Wartość siły magnetycznej zostanie wyznaczona jako pochodna energii magnetycznej $E$ względem wielkości przemieszczenia wirnika wzdłuż osi $O x$ i $O y$. Natomiast moment siły elektromagnetycznej $M_{z}$ jest równy pochodnej mocy $P$ względem prędkości kątowej wirnika $\omega_{z}$. Uwzględniając zależności prądu $i$ oraz indukcyjności własnej $L$ i wzajemnej $M$ uzwojeń dwufazowego silnika bezłożyskowego, równania energii magnetycznej $E$ i mocy $P$ są opisane następującymi zależnościami:

$$
\begin{aligned}
& E=i^{T}\left[\begin{array}{cccc}
L_{m a} & M_{m a m b} & M_{\text {masa }} & M_{\text {masb }} \\
M_{m a m b} & L_{m b} & M_{m b s a} & M_{m b s a} \\
M_{\text {masa }} & M_{m b m a} & L_{s a} & M_{\text {sasb }} \\
M_{\text {masb }} & M_{m b s b} & M_{s a s b} & L_{s b}
\end{array}\right]\left[\begin{array}{c}
i_{4 a} \\
i_{4 b} \\
i_{2 a} \\
i_{2 b}
\end{array}\right] \\
& P=\left[\begin{array}{llll}
u_{m a} & u_{m b} & u_{s a} & u_{s b}
\end{array}\right]\left[\begin{array}{c}
i_{m a} \\
i_{m b} \\
i_{s a} \\
i_{s b}
\end{array}\right]
\end{aligned}
$$

Napięcie prądu elektrycznego przyłożone do uzwojeń silnika $N_{s a}, N_{s b}, N_{m a}$ i $N_{m b}$ jest sumą spadków napięcia na impedancji cewki i siły elektromotorycznej związanej z ruchem wirnika w polu magnetycznym oraz ze zmianą wartości i kierunku w uzwojeniach silnika. Iloczyn indukcyjności $L$ oraz prądu $i$ określa wartość wytwarzanego strumienia magnetycznego $\psi$ skojarzonego przez cewkę o $N$ zwojach; wartość spadku napięcia na impedancji cewek silnika elektrycznego opisuje zależność (4). Oprócz spadku napięcia na impedancji cewki jest również generowana siła elektromotoryczna $u_{\text {ind }}$ wywołana ruchem w polu magnetycznym (równanie (5)). Natomiast strumień magnetyczny $\psi$ opisuje wzór (6).

$$
\begin{aligned}
& u_{r}=\left[\begin{array}{cccc}
R_{m} & 0 & 0 & 0 \\
0 & R_{m} & 0 & 0 \\
0 & 0 & R_{s} & 0 \\
0 & 0 & 0 & R_{s}
\end{array}\right]\left[\begin{array}{l}
i_{m a} \\
i_{m b} \\
i_{s a} \\
i_{s b}
\end{array}\right] \\
& u_{\text {ind }}=-\frac{\mathrm{d} \psi}{\mathrm{d} t}=-\left(\frac{\mathrm{d} L}{\mathrm{~d} t} i+L \frac{\mathrm{d} i}{\mathrm{~d} t}\right)
\end{aligned}
$$




$$
\psi=\left[\begin{array}{l}
\psi_{m a} \\
\psi_{m b} \\
\psi_{s a} \\
\psi_{s b}
\end{array}\right]=\left[\begin{array}{cccc}
L_{m a} & M_{m a m b} & M_{\text {masa }} & M_{\text {masb }} \\
M_{\text {mamb }} & L_{m b} & M_{m b s a} & M_{m b s a} \\
M_{\text {masa }} & M_{m b m a} & L_{s a} & M_{s a s b} \\
M_{\text {masb }} & M_{m b s b} & M_{\text {masb }} & L_{s b}
\end{array}\right]\left[\begin{array}{c}
i_{m a} \\
i_{m b} \\
i_{s a} \\
i_{s b}
\end{array}\right]
$$

Uwzględniając macierz indukcyjności w wyrażeniu na siłę elektromotoryczną $u_{\text {ind }}$, a także fakt, że w macierzy indukcyjności występują wyrażenia określające przemieszczenia $x$ i $y$ w kierunku osi $O x$ i $O y$ oraz że wirnik silnika bezłożyskowego zmienia swoje położenie, to wyrażenia macierzy indukcyjności nie są stałe. Iloczyn pochodnej po czasie macierzy indukcyjności $L$ i wektora prądu $i$ jest opisany równaniem:

$$
\frac{\mathrm{d} L}{\mathrm{~d} t} i=\left[\begin{array}{cccc}
0 & 0 & M^{\prime} \frac{\mathrm{d} x}{\mathrm{~d} t} & -M^{\prime} \frac{\mathrm{d} y}{\mathrm{~d} t} \\
0 & 0 & M^{\prime} \frac{\mathrm{d} y}{\mathrm{~d} t} & M^{\prime} \frac{\mathrm{d} x}{\mathrm{~d} t} \\
M^{\prime} \frac{\mathrm{d} x}{\mathrm{~d} t} & M^{\prime} \frac{\mathrm{d} y}{\mathrm{~d} t} & 0 & 0 \\
-M^{\prime} \frac{\mathrm{d} y}{\mathrm{~d} t} & M^{\prime} \frac{\mathrm{d} x}{\mathrm{~d} t} & 0 & 0
\end{array}\right]\left[\begin{array}{c}
i_{m a} \\
i_{m b} \\
i_{s a} \\
i_{s b}
\end{array}\right]
$$

$$
\begin{aligned}
u & =\left[\begin{array}{cccc}
R_{m} & 0 & 0 & 0 \\
0 & R_{m} & 0 & 0 \\
0 & 0 & R_{s} & 0 \\
0 & 0 & 0 & R_{s}
\end{array}\right]\left[\begin{array}{l}
i_{m a} \\
i_{m b} \\
i_{s a} \\
i_{s b}
\end{array}\right]+j \omega\left[\begin{array}{cccc}
L_{m} & 0 & 0 & 0 \\
0 & L_{m} & 0 & 0 \\
0 & 0 & L_{s} & 0 \\
0 & 0 & 0 & L_{s}
\end{array}\right]\left[\begin{array}{c}
i_{m a} \\
i_{m b} \\
i_{s a} \\
i_{s b}
\end{array}\right]+ \\
& -M\left[\begin{array}{cc}
i_{s a} & -i_{s b} \\
i_{s b} & i_{s a} \\
i_{m a} & i_{m b} \\
i_{m b} & -i_{m a}
\end{array}\right]\left[\begin{array}{l}
\mathrm{d} x \\
\mathrm{~d} t \\
\mathrm{~d} y \\
\mathrm{~d} t
\end{array}\right]-\left[\begin{array}{cccc}
L_{m a} & 0 & M x & -M y \\
0 & L_{m b} & M y & M x \\
M x & M y & L_{s a} & 0 \\
-M y & M x & 0 & L_{s b}
\end{array}\right]\left[\begin{array}{c}
\frac{\mathrm{d} i_{m a}}{\mathrm{~d} t} \\
\frac{\mathrm{d} i_{m b}}{\mathrm{~d} t} \\
\frac{\mathrm{d} i_{s a}}{\mathrm{~d} t} \\
\frac{\mathrm{d} i_{s b}}{\mathrm{~d} t}
\end{array}\right]
\end{aligned}
$$

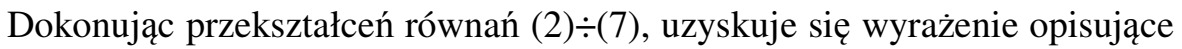
napięcie prądu elektrycznego dla poszczególnych uzwojeń silnika bezłożyskowego (8). W silniku bezłożyskowym występują dwa układy współrzędnych: układ nieruchomy związany ze statorem oraz ruchomy związany $\mathrm{z}$ wirnikiem. 
Podczas analizy przyjęto, że ruch wirnika w kierunku przeciwnym do ruchu wskazówek zegara oznacza dodatnią wartość przemieszczenia kątowego. Prądy przepływające przez uzwojenia silnikowe $i_{m a}, i_{m b}$ wytwarzają siłę magnetyczną. Natomiast prąd przepływający przez uzwojenia lewitacyjne oznaczono $i_{s a}, i_{s b}$. Uwzględniając przedstawione zależności, model silnika opisano równaniem mechanicznym w postaci macierzowej oraz równaniem elektrycznym $[1,4]$ :

$\left[\begin{array}{ccc}m & 0 & 0 \\ 0 & m & 0 \\ 0 & 0 & J\end{array}\right]\left[\begin{array}{l}\ddot{x} \\ \ddot{y} \\ \ddot{\varphi}\end{array}\right]=$
$=\left[\begin{array}{cccc}M I_{m e} \cos (2 \omega t+\theta) & M I_{m e} \sin (2 \omega t+\theta) & 0 & 0 \\ M I_{m e} \sin (2 \omega t+\theta) & -M I_{m e} \cos (2 \omega t+\theta) & 0 & 0 \\ 0 & 0 & -\psi_{m} \sin (2 \omega t) & \psi_{m} \cos (2 \omega t)\end{array}\right]\left[\begin{array}{c}i_{s a} \\ i_{s b} \\ i_{m a} \\ i_{m b}\end{array}\right]+\left[\begin{array}{c}G_{x} \\ G_{y} \\ -M_{o}\end{array}\right]$

\section{Wyniki badań}

Pierwszym z analizowanych parametrów był rozkład wartości pola magnetycznego na powierzchni statora $\mathrm{z}$ magnesami trwałymi. Wyniki analiz MES przedstawiono na rys. 4a. Jak widać, pole pojedynczego bieguna jest polem niejednorodnym, w którym występują miejsca o zwiększonej wartości pola magnetycznego. Związane jest to z tym, że w konstrukcji wirnika wykorzystano magnesy neodymowe o wymiarach $10 \times 2,5 \times 1 \mathrm{~mm}$ z kierunkiem magnesowania
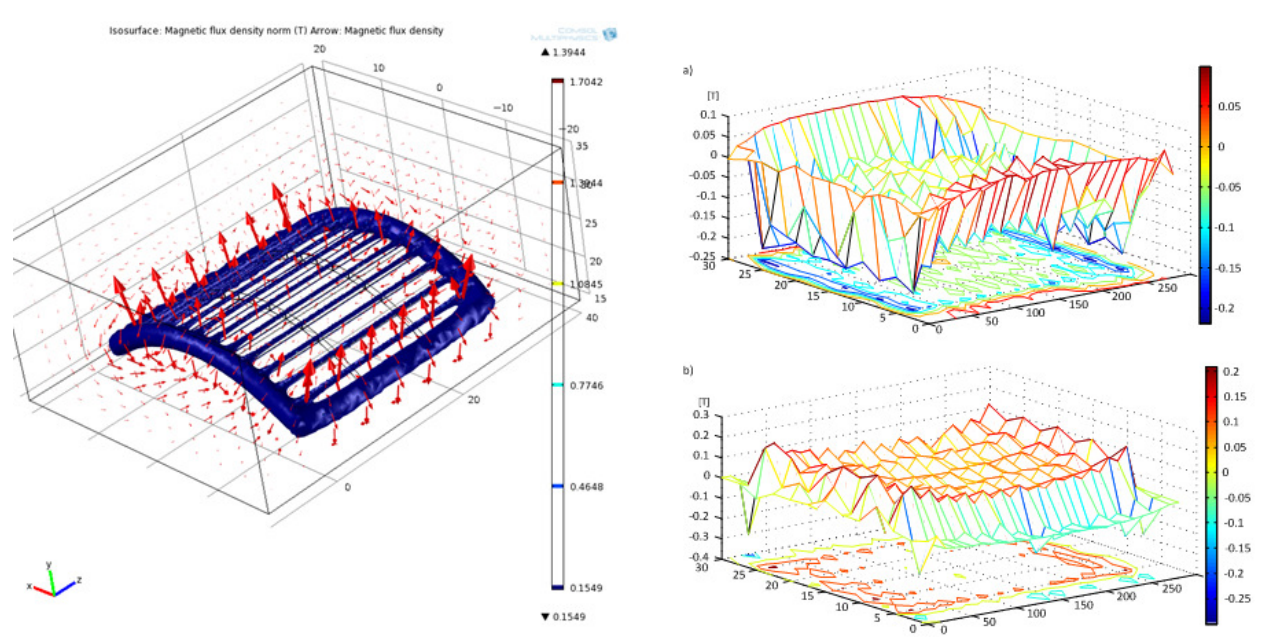

Rys. 4. Zasada generowania siły magnetycznej w silniku bezłożyskowym $[1,2]$

Fig. 4. The principle of magnetic force generation in the bearingless motor [1, 2] 
wzdłuż wymiaru $1 \mathrm{~mm}$. Na pojedynczy biegun wirnika składa się tablica z 65 magnesów. Analizy teoretyczne zostały potwierdzone przez badania eksperymentalne (rys. 4b). Pomiary były wykonywane na granicy i na środku magnesu, z którego została zbudowana tablica magnesów nabiegunnika maszyny elektrycznej $[1,2]$.

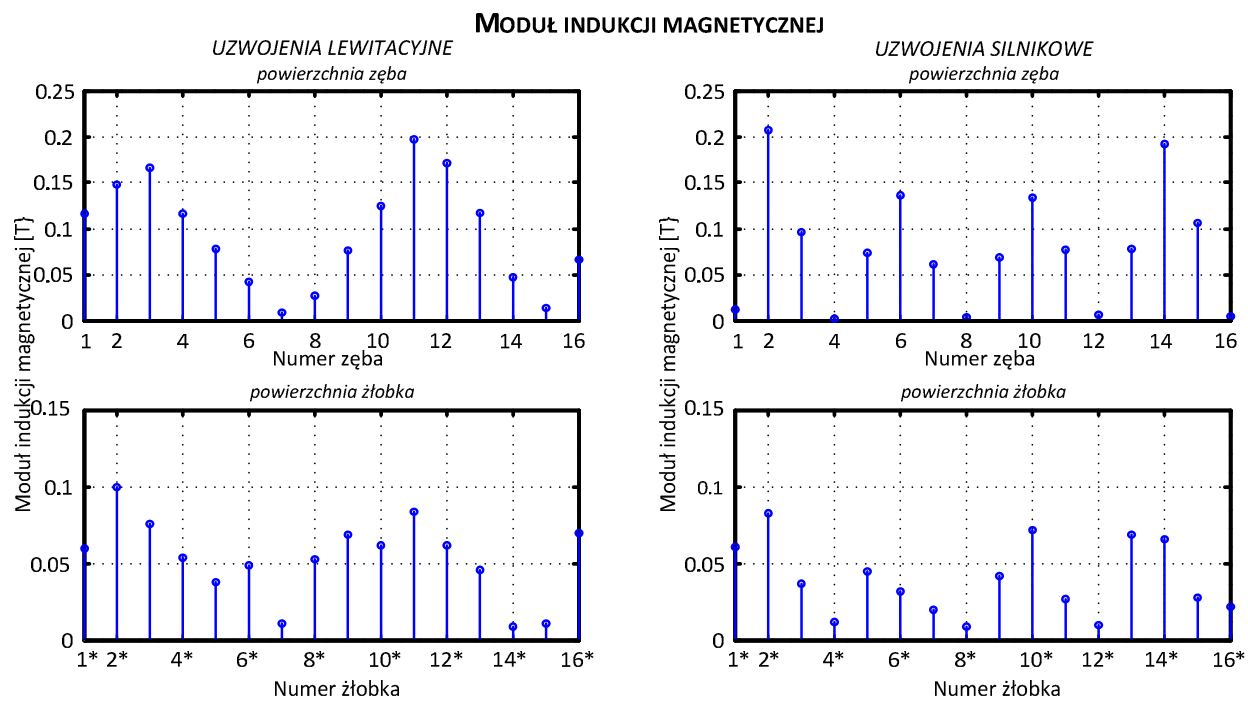

Rys. 5. Moduł indukcji magnetycznej w szczelinie statora silnika dwufazowego [2, 5]

Fig. 5. The module of magnetic induction in the gap of the stator of the two-phase motor $[2,5]$

$\mathrm{Na}$ rysunku 5. pokazano wyniki eksperymentalne modułu strumienia magnetycznego na obwodzie statora wewnątrz z i bez wirnika stalowego. Przedstawiony rozkład indukcji magnetycznej potwierdza wyniki analiz teoretycznych. Przedstawiono oddzielnie rozkład strumienia na zębach i żłobkach statora. Charakter rozkładu strumienia w układach z i bez wirnika jest analogiczny. Na powierzchni zębów w układzie $\mathrm{z}$ wirnikiem maksymalna wartość indukcji magnetycznej wynosi $166 \cdot 10^{-3} \mathrm{~T}$, a minimalna $197 \cdot 10^{-3} \mathrm{~T}$. Na rysunku 6 . przedstawiono przebieg parametrów rezystancji, impedancji i indukcyjności własnej uzwojeń silnika. Z otrzymanych charakterystyk wynika, że wartość liniowa charakterystyki mieści się w zakresie do $100 \mathrm{~Hz}$. Dla szeregowego modelu uzwojenia rezystancja zmienia się od 3,05 $\Omega\left(N_{s a}\right)$ i 3,04 $\Omega\left(N_{s b}\right)$ dla częstotliwości $20 \mathrm{~Hz}$ do $4,1 \Omega\left(N_{s a}\right)$ i $4,08 \Omega\left(N_{s b}\right)$. Parametry uzwojeń silnikowych wynoszą $4,54 \Omega\left(N_{m a}\right)$ i $4,57 \Omega\left(N_{m b}\right)$ dla częstotliwości $20 \mathrm{~Hz}$ oraz $5 \Omega\left(N_{m a}\right)$ i $5,05 \Omega$ $\left(N_{m b}\right)$ dla częstotliwości $100 \mathrm{~Hz}$. Natomiast rezystancja zmienia się od 38,2 $\mathrm{mH}$ $\left(N_{s a}\right)$ i $37,9 \mathrm{mH}\left(N_{s b}\right)$ dla częstotliwości $20 \mathrm{~Hz}$ do $38,1 \mathrm{mH}\left(N_{s a}\right)$ i $37,7 \mathrm{mH}\left(N_{s b}\right)$. Parametry uzwojeń silnikowych wynoszą odpowiednio $40,3 \mathrm{mH}\left(N_{m a}\right)$ i $40,1 \mathrm{mH}$ 
$\left(N_{m b}\right)$ dla częstotliwości $20 \mathrm{~Hz}$. Jak wynika z otrzymanych wyników, w zakresie roboczym do $100 \mathrm{~Hz}$ indukcyjność własna ma wartość stałą, a impedancje wszystkich uzwojeń się pokrywają.
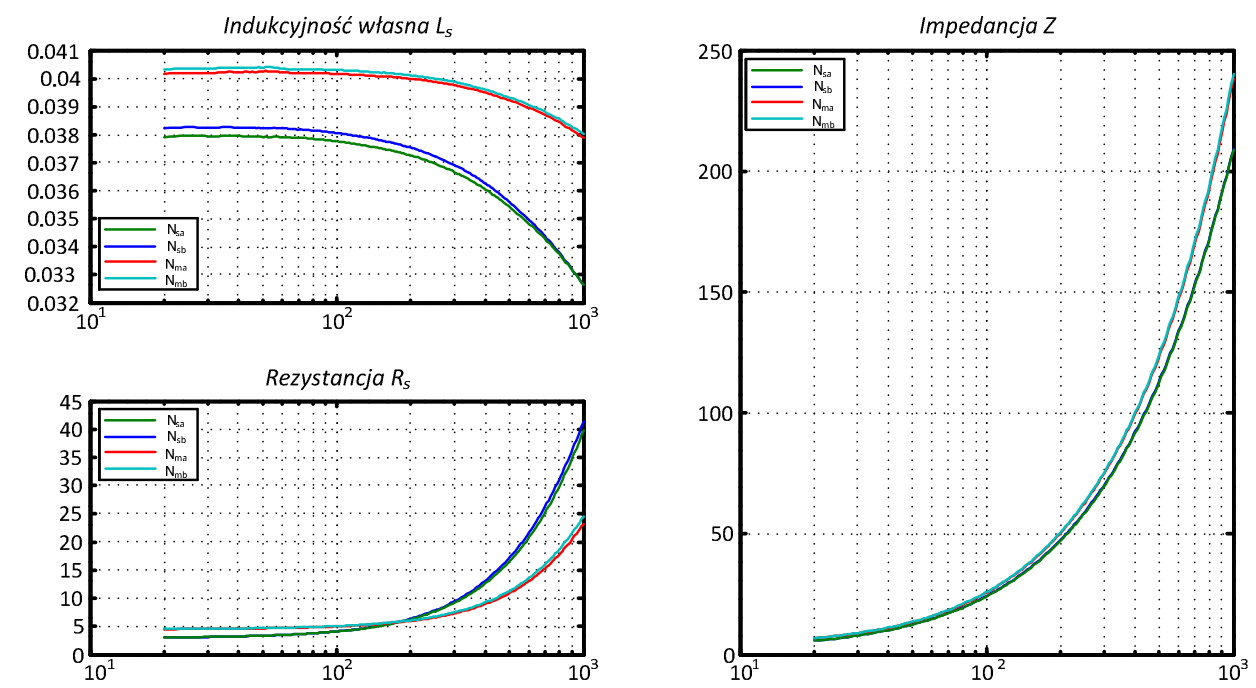

Rys. 6. Charakterystyka parametrów elektrycznych silnika bezłożyskowego [5]

Fig. 6. The characteristics of electric parameters of the bearingless motor [5]

\section{Podsumowanie}

Prace badawcze prowadzone obecnie w Wojskowej Akademii Technicznej stanowią odpowiedź na panujące w tej dziedzinie tendencje. Współczesne statki powietrzne są projektowane zgodnie z koncepcją More Electric Aircraft. Nowa konstrukcja bezłożyskowego silnika elektrycznego jest ukierunkowana zarówno na eliminację elementów ograniczających szybkość działania takich układów, jak również na poprawę ich parametrów pracy oraz warunków eksploatacji (eliminacja sił tarcia, chłodzenie, uproszczenie konstrukcji itp.). Dodatkowo przedstawione rozwiązania eliminują lub ograniczają wpływ elementów nieliniowych, takich jak strefa nieczułości, histereza. Oprócz poprawy parametrów technicznych zastosowanie nowych rozwiązań poprawia bezpieczeństwo i niezawodność konstrukcji lotniczych.

\section{Literatura}

[1] Henzel M., Falkowski K., Mazurek P.: Model matematyczny i symulacyjny bezłożyskowego silnika z magnesami trwałymi. Pomiary Automatyka Robotyka, 2/2012, 450-455. 
[2] Henzel M., Falkowski K.: Raport z pracy badawczej własnej nr O N509 165238. WAT, Warszawa 2012.

[3] Chiba A., Fukao T., Ichikawa O., Oshima M., Takemoto M., Dorrell D.: Magnetic bearings and bearingless drives. Elsevier's Science Technology Rights Department in Oxford, UK 2005.

[4] Henzel M.: Mathematical analysis and investigation results of the bearingless electric motor with permanent magnets. Solid State Phenomena, vol. Mechatronic Systems and Materials IV, Trans Tech Publications, 2013, 354-359.

[5] Henzel M., Falkowski K.: Determination of inductance matrixes of bearingless electric motor for magnetic levitation. Pomiary Automatyka Robotyka, 2/2013, s. 563.

\title{
BEARINGLESS ELECTRIC MACHINES IN MORE ELECTRIC AIRCTRAFT CONCEPT
}

\begin{abstract}
A bstract
Nowadays in aviation the dynamic development of aircraft on-board equipment connected with implementation of More Electric Aircraft technology which assumed the application of a larger number of systems using electric energy has been observed. The conception offers the possibility of using conditions improvement of installations and systems ensuing from mass reduction, increased reliability of devices, easier maintenance and by these the increasing flight safety. Responding to these tendencies in Department of Avionics and Air Force Equipment at Military University of Technology the constructions of bearingless electric motors (motors, generators, generator-starters) have been developed. In the article an example of bearingless electric motor with permanent magnets is presented. The construction of bearingless electric motor designed according to More Electric Aircraft conception, which are directed at elimination of elements limiting working speed and also at improvement of working parameters and operating conditions. The mathematical model of such engine and results of both simulated and experimental studies have been presented.
\end{abstract}

Keywords: bearingless electric motors, aircrafts, reliability

DOI:10.7862/rm.2013.22

Otrzymano/received: 15.09 .2013

Zaakceptowano/accepted: 22.10 .2013 